\title{
Heterogeneity in Subcortical Brain Development: A Structural Magnetic Resonance Imaging Study of Brain Maturation from 8 to 30 Years
}

\author{
Ylva Østby, ${ }^{1}$ Christian K. Tamnes, ${ }^{1}$ Anders M. Fjell, ${ }^{1,2}$ Lars T. Westlye, ${ }^{1}$ Paulina Due-Tønnessen, ${ }^{3}$ \\ and Kristine B. Walhovd ${ }^{1,2}$ \\ ${ }^{1}$ Center for the Study of Human Cognition, Department of Psychology, University of Oslo, N-0317 Oslo, Norway, ${ }^{2}$ Department of Neuropsychology, \\ Ullevaal University Hospital, N-0407 Oslo, Norway, and 3 Department of Radiology, Rikshospitalet University Hospital, N-0027 Oslo, Norway
}

\begin{abstract}
Brain development during late childhood and adolescence is characterized by decreases in gray matter (GM) and increases in white matter (WM) and ventricular volume. The dynamic nature of development across different structures is, however, not well understood, and the present magnetic resonance imaging study took advantage of a whole-brain segmentation approach to describe the developmental trajectories of 16 neuroanatomical volumes in the same sample of children, adolescents, and young adults $(n=171$; range, $8-30$ years). The cerebral cortex, cerebral WM, caudate, putamen, pallidum, accumbens area, hippocampus, amygdala, thalamus, brainstem, cerebellar GM, cerebellar WM, lateral ventricles, inferior lateral ventricles, third ventricle, and fourth ventricle were studied. The cerebral cortex was further analyzed in terms of lobar thickness and surface area. The results revealed substantial heterogeneity in developmental trajectories. GM decreased nonlinearly in the cerebral cortex and linearly in the caudate, putamen, pallidum, accumbens, and cerebellar GM, whereas the amygdala and hippocampus showed slight, nonlinear increases in GM volume. WM increased nonlinearly in both the cerebrum and cerebellum, with an earlier maturation in cerebellar WM. In addition to similarities in developmental trajectories within subcortical regions, our results also point to differences between structures within the same regions: among the basal ganglia, the caudate showed a weaker relationship with age than the putamen and pallidum, and in the cerebellum, differences were found between GM and WM development. These results emphasize the importance of studying a wide range of structural variables in the same sample, for a broader understanding of brain developmental principles.
\end{abstract}

\section{Introduction}

Subcortical structures are important in developmental disorders (Krain and Castellanos, 2006), and we need a better understanding of the dynamics of differential subcortical brain development. However, few magnetic resonance imaging (MRI) studies cover normal brain development in multiple subcortical regions in childhood and adolescence. The aim of the present study was to describe and compare the developmental trajectories of several subcortical structures in the same sample of participants, thereby shedding light on the dynamic interplay between different brain structures in development.

It is generally acknowledged that gray matter (GM) volume increases in early childhood and decreases during adolescence (Jernigan et al., 1991; Reiss et al., 1996; Giedd et al., 1999; Sowell et al., 1999, 2002; Lenroot et al., 2007; Wilke et al., 2007; Shaw et

Received March 13, 2009; revised July 7, 2009; accepted Aug. 3, 2009.

This work was supported by the Norwegian Research Council (177404/W50 and 186092/V50 to K.B.W., 170837/ V50 to Ivar Reinvang); the University of Oslo (K.B.W.); and the Department of Psychology, University of 0slo (A.M.F.). We thank Mari Torstveit, Victoria Torp Sells, and Vivi Agnete Larsen for contributing to the data acquisition; Dag Erik Eilertsen for assistance in statistical analyses; and Inge Amlien and Tonje Østby for help with preparation of the figures. We also thank all participants and their parents for taking part in this study.

Correspondence should be addressed to Ylva Østby, Department of Psychology, University of Oslo, P.0. Box 1094 Blindern, N-0317 0slo, Norway. E-mail: ylva.ostby@psykologi.uio.no.

D01:10.1523/JNEUROSCI.1242-09.2009

Copyright $\odot 2009$ Society for Neuroscience ～0270-6474/09/2911772-11\$15.00/0 al., 2008). This may, in part, reflect early synaptic arborization and later pruning (Huttenlocher, 1990). Results indicate that subcortical GM structures show differential developmental trajectories (Giedd et al., 1996b; Sowell et al., 2002; Toga et al., 2006). Because most studies have quantified only one or a few structures, the relative development of the subcortical structures is still unclear, however. For instance, different emphasis has been put on either the caudate or lenticular nuclei in development in various reports, sometimes because of methodological constraints (Jernigan et al., 1991; Giedd et al., 1996a; Sowell et al., 1999, 2002; Wilke et al., 2007). There has been some focus on structural development of the cerebellum (Sowell et al., 2002; Liu et al., 2003; Mackie et al., 2007) and accumbens (Sowell et al., 2002), but cerebellar development is still not characterized in terms of separate WM and GM development. Furthermore, there is a need for a broader understanding of the development of hippocampus and amygdala, as these structures often appear to increase during development, although discrepancies exist (Giedd et al., 1996b; Sowell et al., 2002; Gogtay et al., 2006; Toga et al., 2006; Guo et al., 2007). It is not clear how this is to be understood within a (proposed) framework of arborization/ pruning as general principles of GM development. White matter (WM) volume has been shown to increase, often linearly, probably driven by increased myelination during adolescence and early adulthood (Reiss et al., 1996; Giedd et al., 1999; Sowell et al., 2002; 
Table 1. Age and sex distribution of the sample

\begin{tabular}{lllr}
\hline & \multicolumn{2}{l}{ Sex } & \\
\cline { 2 - 3 } Age group & Female & Male & Total \\
\hline $8-11$ & 17 & 21 & 38 \\
$12-15$ & 19 & 18 & 37 \\
$16-19$ & 19 & 17 & 36 \\
$20-23$ & 17 & 16 & 33 \\
$24-31$ & 15 & 12 & 27 \\
Total & 87 & 84 & 171 \\
\hline
\end{tabular}

Lenroot et al., 2007). However, developmental trajectories for WM in the cerebrum versus cerebellum have not been compared.

In the current study, maturational changes were described and compared across volume estimates for the caudate, putamen, pallidum, accumbens area, amygdala, hippocampus, thalamus, cerebellar cortex and WM, brainstem, cerebral cortex and WM, and ventricles (lateral ventricles, inferior lateral ventricles, third ventricle, fourth ventricle), along with volume, thickness, and surface area estimates of the cortical lobes. Especially, it was investigated how subcortical structures develop compared with the cerebral cortex, how the basal ganglia/striatal structures compare in development, how the amygdala and hippocampus develop, and how cerebellar development can be described in terms of separate GM and WM volume.

\section{Materials and Methods}

Sample. One hundred seventy-one children and young adults ( 87 females and 84 males) were included. The age and sex distributions are shown in Table 1. Pearson's $\chi^{2}$ test revealed no differences in gender distribution for the age groups shown in Table 1 (Pearson's $\chi^{2}=0.870 ; p=0.93$ ). Children and adolescents between 8 and 19 years of age were recruited through newspaper advertisements, and local schools and workplaces. Adult participants were recruited through newspaper advertisements and among university students. The project was approved by the Regional Ethical Committee of South Norway. Written informed consent was obtained from all participants from 12 years of age and from the parent/guardian for participants $<18$ years. Oral informed consent was given by participants $<12$ years of age. Participants had no self- or parent-reported history of neurological or psychiatric disorders, chronic illness, premature birth, learning disabilities, or use of medicines known to affect nervous system functioning. They were required to be right handed, as reported in a structured interview (performed with participants $\geq 12$ years and with parents of participants aged 8-19), to speak Norwegian fluently, to have normal or corrected-to-normal hearing and vision, and to have no MRI contraindications. Participants were tested using the WASI (Wechsler Abbreviated Scale of Intelligence) (Wechsler, 1999), and all participants scored above 80 on full-scale intelligence quotient [IQ; M (mean), 110.27; SD, 9.96]. There was no difference in IQ between males $(\mathrm{M}, 111.8 ; \mathrm{SD}, 10.5)$ and females $\left(\mathrm{M}, 109.2 ; \mathrm{SD}, 9.2 ; t_{(168)}\right.$ $=-1.697 ; p=0.10)$. Among the 176 children and adolescents who met inclusion criteria, 4 had no useable MRI scans because of movement artifacts. All participants' scans were examined by a neuroradiologist, which led to the exclusion of one additional participant, reducing the total number of participants to 171 .

MRI acquisition and analysis. Imaging data were collected using a 12channel head coil on a 1.5 tesla Siemens Avanto scanner (Siemens Medical Solutions). The pulse sequences used for the morphometric analyses were two three-dimensional, T1-weighted [magnetization prepared rapid gradient echo (MP-RAGE)] scans, with the following parameters: repetition time, $2400 \mathrm{~ms}$; echo time, $3.61 \mathrm{~ms}$; inversion time, $1000 \mathrm{~ms}$; flip angle, $8^{\circ}$; matrix, $192 \times 192$; field of view, 192. Each scan took $7 \mathrm{~min}$, $42 \mathrm{~s}$. Each volume consisted of 160 sagittal slices with voxel sizes of $1.25 \times$ $1.25 \times 1.20 \mathrm{~mm}$. Each MP-RAGE was visually inspected, and only scans deemed to have no or minimal movement artifacts were included in analyses. The two MP-RAGEs were averaged to increase the signal-tonoise-ratio. Where there were problems achieving two high-quality scans attributable to motion artifacts, etc., only one scan was used in the analysis. This was the case for $15.2 \%$ of the participants, of whom most (73\%) were $<12$ years of age.

All datasets were processed and analyzed at the Neuroimaging Analysis Lab, Center for the Study of Human Cognition, University of Oslo, with additional use of computing resources from the Titan High Performance Computing facilities (http://hpc.uio.no/index.php/Titan) at the University of Oslo. Volumes of the caudate, putamen, pallidum, accumbens, thalamus, hippocampus, amygdala, cerebellum cortex, cerebellum WM, ventricles, and total cerebral WM were calculated using FreeSurfer 4.0.5. (http://surfer.nmr.mgh.harvard.edu/fswiki). The automated segmentation procedure was described previously (Fischl et al., 2002) and automatically assigns a neuroanatomical label to each voxel in a MR volume based on probabilistic information automatically estimated from a manually labeled training set. The segmentation puts constraints on allowable locations of structures in relation to each other based on the training set (e.g., hippocampus is never anterior to amygdala). The automated segmentations have been found to be statistically indistinguishable from manual labeling (Fischl et al., 2002), and correlations between FreeSurfer segmentation and manual labeling of hippocampal volume reached 0.85 in a study by Tae et al. (2008). Reproducibility errors between scan sessions have been shown to be up to $2.3 \%$ in young adults, with higher error estimates for the smallest structures (Jovicich et al., 2009). The segmentations were visually inspected for accuracy, and none were discarded. The segmentation is exemplified in Figures 1 and 2. As can be seen in Figure 2, the ventricles are only partly segmented, particularly the third ventricle and the inferior lateral ventricle. This should be kept in mind when considering the results. Although the brainstem is not segmented further into separate WM and GM volumes, it is considered together with WM volumes in this study.

Cortical volume, thickness, and area. Regional cortical thickness was estimated using FreeSurfer 4.1 (http://surfer.nmr.mgh.harvard.edu/ fswiki) by means of an automated surface reconstruction procedure described previously (Dale et al., 1999; Fischl et al., 1999a,b, 2001; Fischl and Dale, 2000; Segonne et al., 2004). Briefly, a representation of the GM/WM boundary was reconstructed (Dale et al., 1999), using intensity and continuity information from the entire MR volume in segmentation and deformation procedures. Minor manual editing of vessels and dura was routinely performed, according to FreeSurfer guidelines (see http://surfer.nmr.mgh.harvard.edu/fswiki). The cortical surface was automatically parcellated based on (1) the probability of each label at each location in a surface-based atlas space, based on a manually parcellated training set; (2) local curvature information; and (3) contextual information, encoding spatial neighborhood relationships between labels (conditional probability distributions derived from the manual training set) resulting in 33 neuroanatomical regions (Fischl et al., 2004; Desikan et al., 2006). All resulting labels were manually inspected for accuracy. The results of these regional analyses of the 33 parcels were presented previously (Tamnes et al., 2009). In the present study, the mean lobar thickness (frontal, parietal, temporal, and occipital lobe) is reported, based on bilateral combinations of parcels, as well as total cortical mean thickness. The surface-based analysis also yielded estimates of the regional cortical (pial) area of each of the 33 parcels, which in turn were combined into a bilateral lobar area (frontal, parietal, temporal, and occipital) and a total cortical area. Cortical volume was calculated by multiplying cortical surface area with mean cortical thickness. Parcels were combined into bilateral lobar volumes. The surface-based (thickness) analyses have been shown to be comparable to postmortem pathological analyses, with agreement between pathological measurements and automated thickness estimation within $0.20 \mathrm{~mm}$ (Rosas et al., 2002). Test-retest variability in cortical thickness measurements across weeks and across scanner platforms has been shown to be within $0.20 \mathrm{~mm}$ in most of the cerebral cortex (Han et al., 2006), and correlations between cortical thickness and cognitive performance were shown by Dickerson et al. (2008) to be comparable across scan sessions, scanner platforms, and field strengths.

Total brain volume (TBV) was calculated based on all GM and WM volumes and ventricular volumes. 
a Thalamus

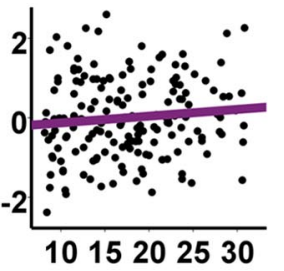

e Brainstem

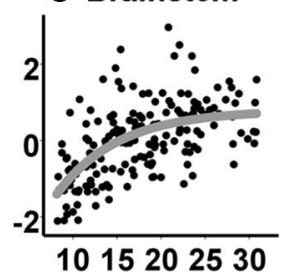

9 Caudate

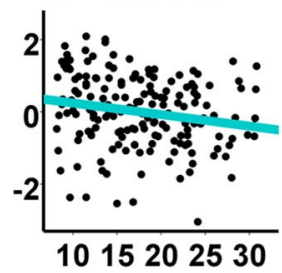

i Accumbens area

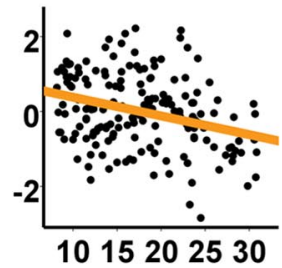

K Amygdala

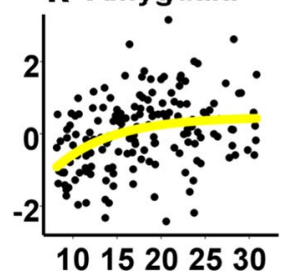

b Cerebral cortex
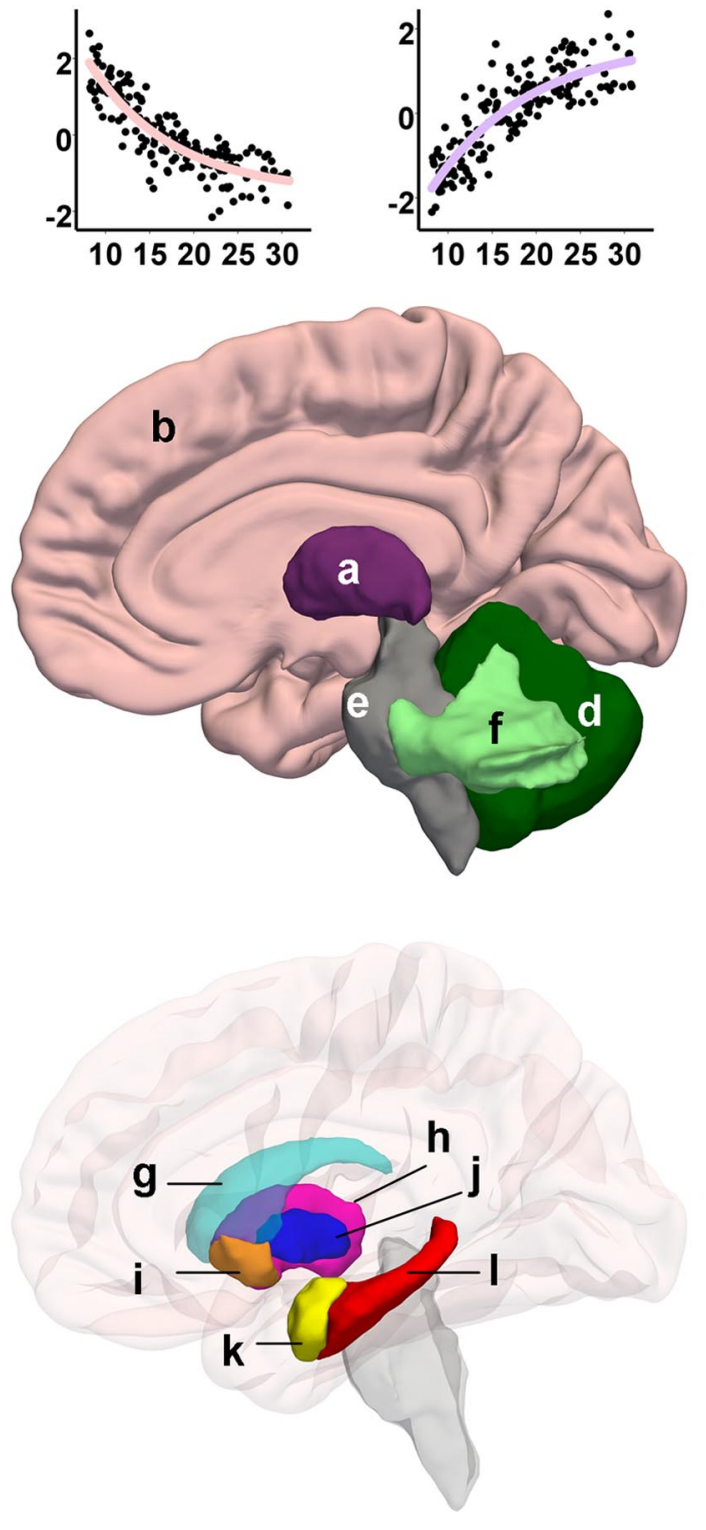

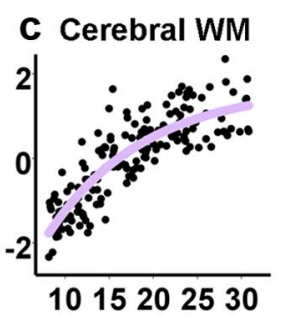

d Cerebellum GM

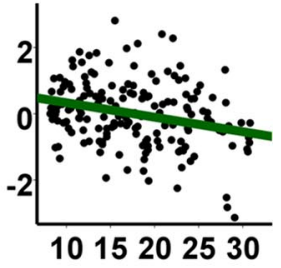

f Cerebellum WM

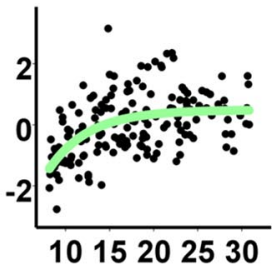

h Putamen

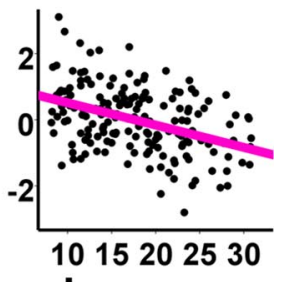

j Pallidum

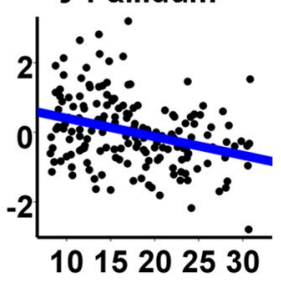

I Hippocampus

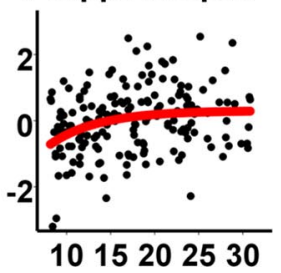

Figure 1. Regression plots showing the relationship between age and bilateral volumes of thalamus ( $(\boldsymbol{a})$, cerebral cortex $(\boldsymbol{b})$, cerebral WM (c), cerebellum GM (d), brainstem $(\boldsymbol{e})$, cerebellum WM $(\boldsymbol{f})$, caudate $(\boldsymbol{g})$, putamen $(\boldsymbol{h})$, the accumbens area $(\boldsymbol{i})$, pallidum $(\boldsymbol{j})$, amygdala $(\boldsymbol{k})$, and hippocampus $(\boldsymbol{I})$, with age on the horizontal axis and TBV-corrected volume in $z$-scores on the vertical axis. Also displayed are samples of the segmentation (cerebral WM not shown), based on the group mean.

Statistical analysis. Regression analyses were performed on three sets of volumetric variables: raw volumes, residual volumes after correcting for TBV (the sum of all 16 brain and ventricular volumes) by regression analyses, and proportional volumes of TBV. The choice of these types of variables is based on the assumption that each measure may be useful in its particular way, elucidating different aspects of development. On the one hand, the actual increase and decrease in each volume needs to be taken into account, and hence the raw volumes were analyzed and displayed in regression plots (see Table 3 and supplemental Fig. 1, available at www.jneurosci.org as supplemental material). On the other hand, there is substantial individual variance in brain size, which is bound to affect individual brain volumes both within and across age groups. This variance is, among other things, related to physical parameters such as height (Peters et al., 1998) and sex (Giedd et al., 1997; Sowell et al., 2007), which may create noise in the data that can obscure the unique effects of age. Several approaches to correcting for individual differences in brain volumes exist, including correcting for intracranial volume (ICV) (Walhovd et al., 2005) and TBV, with or without ventricles (Sowell et al., 2002; Wilke et al., 2007). Since ICV correlated positively with age in our sample $(r=0.37 ; p<0.001)$, correcting for this variable would also take out some of the effects of age. TBV did not correlate significantly with age $(r=-0.09 ; p=0.26)$, thus being better suited to control for individual differences without removing the effect of age. Brain development is characterized by a complex interplay between regressive and progressive events, and this should be taken into consideration in the interpretation of TBV-corrected results. How each volume relates to the rest of the brain throughout development may be conceptualized as each volume's proportion of the TBV (Jernigan et al., 1991; Sowell et al., 2002), and hence this measure was also used in the analyses. Cortical thickness and surface area variables were analyzed without TBV correction, as thickness analyses are often done without such correction (Sowell et al., 2004; Shaw et al., 2008; Tamnes et al., 2009), and we wanted to be able to compare thickness and surface area as aspects of cortical development. The matter of correction in the case of surface area is less straight forward, though (Panizzon et al., 2009). Regression analyses were performed with all measures separately as criterion variables and age as the 

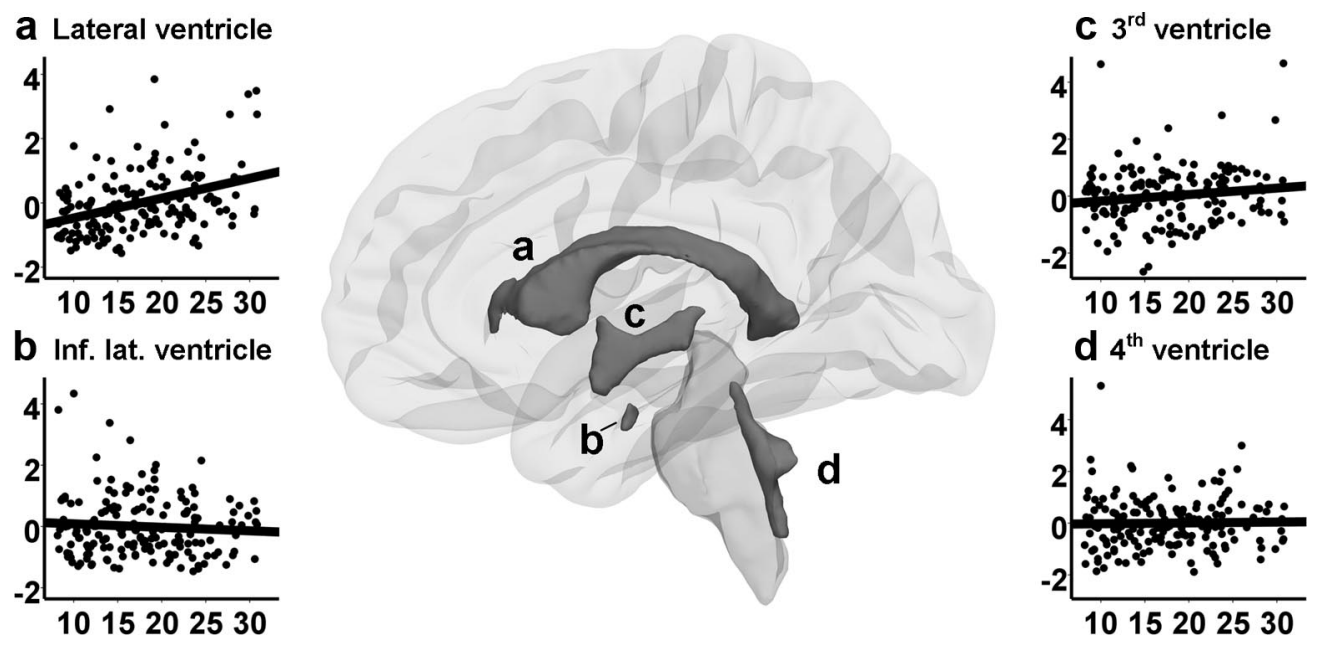

Figure 2. Regression plots showing the relationship between age and bilateral volumes of the lateral ventricles $(\boldsymbol{a})$, the inferior lateral ventricles $(\boldsymbol{b})$, the third ventricles ( $\boldsymbol{c}$ ), and the fourth ventricles $(\boldsymbol{d})$, with age on the horizontal axis and TBV-corrected volume in z-scores on the vertical axis, shown together with samples of the segmentation, based on the group mean.

Table 2. Raw volumes of brain structures and ventricles

\begin{tabular}{|c|c|c|c|c|c|c|}
\hline & \multicolumn{6}{|l|}{ Age groups } \\
\hline & $8-11(n=38)$ & $12-15(n=37)$ & $16-19(n=36)$ & $20-23(n=33)$ & $24-31(n=27)$ & Total $(n=171)$ \\
\hline Cerebral cortex & $576,253(47,504)$ & $560,231(53,479)$ & $509,614(48,172)$ & $492,307(32,649)$ & $487,303(49,454)$ & $528,512(58,970)$ \\
\hline WM & $423,665(50,171)$ & $479,170(47,799)$ & $469,127(57,028)$ & $491,376(49,735)$ & $504,704(70,491)$ & $471,109(60,860)$ \\
\hline Hippocampus & $8535(802)$ & $8995(648)$ & $8824(828)$ & $8922(690)$ & $8874(787)$ & $8824(763)$ \\
\hline Amygdala & 3478 (324) & $3750(395)$ & $3660(440)$ & $3722(465)$ & $3741(461)$ & $3664(424)$ \\
\hline Caudate & $8261(993)$ & $8216(862)$ & $7848(815)$ & 7765 (704) & 7765 (909) & 7990 (882) \\
\hline Putamen & $12,805(1352)$ & $12,747(982)$ & $12,297(1208)$ & $11,697(1023)$ & $11,635(1207)$ & $12,287(1250)$ \\
\hline Pallidum & $3721(358)$ & 3837 (372) & $3582(389)$ & $3463(257)$ & $3486(400)$ & $3630(382)$ \\
\hline Accumbens & 1467 (145) & $1467(180)$ & 1409 (163) & $1393(178)$ & $1309(203)$ & $1415(180)$ \\
\hline Thalamus & $14,294(1238)$ & $14,947(1006)$ & $14,104(1251)$ & $14,365(892)$ & $14,498(1373)$ & $14,441(1181)$ \\
\hline Cerebellum GM & $121,069(9770)$ & $124,302(12,420)$ & $116,799(10356)$ & $11,7831(13,254)$ & $114,138(12,023)$ & $119,150(11,950)$ \\
\hline Cerebellum WM & $26,135(2538)$ & $29,241(3766)$ & $28,658(2784)$ & $29,831(3399)$ & $29,727(2347)$ & $28,619(3311)$ \\
\hline Brainstem & $19,046(1741)$ & $21,166(2346)$ & $20,521(1928)$ & $21,558(2281)$ & $21,741(1856)$ & $20,725(2253)$ \\
\hline Lateral ventricle & $8909(4195)$ & $11,043(6526)$ & $12,926(7269)$ & $12,509(6163)$ & $16,105(8682)$ & $12,048(6903)$ \\
\hline Inferior lateral ventricle & $571(341)$ & $625(306)$ & $650(297)$ & $539(225)$ & $526(245)$ & $586(290)$ \\
\hline Third ventricles & $906(213)$ & 967 (199) & $904(213)$ & $921(205)$ & $1019(270)$ & $940(220)$ \\
\hline Fourth ventricles & $1641(680)$ & $1669(470)$ & $1582(369)$ & $1604(530)$ & 1692 (558) & $1636(527)$ \\
\hline Total brain volume & $1,218,700(102,670)$ & $1,268,100(101,391)$ & $1,196,400(112,006)$ & $1.204,200(91,544)$ & $1,208,900(129,920)$ & $1,220,400(109,094)$ \\
\hline
\end{tabular}

Mean (SD) number of voxels in each raw volume measured (summed across hemispheres), for each age group and for the total sample. One voxel equals $1 \mathrm{~mm}^{3}$.

predictor variable. The analyses were repeated with age ${ }^{2}$ as an additional predictor to assess possible quadratic components, and again with age ${ }^{3}$ as a third predictor, to assess possible cubic components. Regression analyses were then performed with all measures separately as the criterion variable and TBV, age, and (where the previous analyses had shown a nonlinear component) age $^{2}$ as the simultaneous predictor variables, to show the relative contributions of each variable on the brain volumes. For volumes in which age ${ }^{2}$ gave a significant contribution, exponential curves were calculated. The data points were fitted iteratively to exponential functions of the form $f(x)=b_{1}+b_{2} \times \mathrm{e}^{(- \text {age/t)}}$, where $b_{1}$ is the estimated value at the asymptote, $b_{2}$ is the difference between $b_{1}$ and the estimated value of $x$ at age zero, and $t$ is a time constant reflecting rate of development. The effect size of each exponential curve fit is indicated by $R^{2}$. For both the exponential and linear fits, absolute and relative change in volume from 8 to 30 years was calculated. The relative change of nonlinearly developing volumes was calculated from the exponential function. As correlations between the different brain structures were expected, Bonferroni corrections for multiple comparisons should be considered overly conservative. Still, Bonferroni-corrected results are also reported, with a $p$ value threshold of 0.003 in the volumetric analysis (based on 16 volumes) and a threshold of 0.006 in the regional cortical analyses (based on four lobes $\times$ two variables, thickness and surface area, whereas total cortical volume is Bonferroni corrected in the volumetric analysis and the regional volumes are dependent on the thickness and surface areas). Within designated regions, the differences in relationships with age were tested statistically using $t$ tests of Fisher's $z$-transformed correlations. This was done to statistically compare age trajectories where it was deemed theoretically and statistically appropriate. Two regions were selected for this analysis based on proximity and apparent similarities in trajectories: the basal ganglia (caudate, putamen, and pallidum) and the medial temporal lobe subcortical structures (hippocampus and amygdala).

\section{Results}

\section{Descriptive analyses}

ANOVA with 13 bilateral brain volumes and two hemispheres as within-subjects factors and age as the between-subject factor showed no significant hemisphere $\times$ age interaction effects $\left(F_{(124,46)}=1.104 ; p=0.36\right)$. This analysis was repeated for four bilateral regional (cortical lobe) variables, yielding no significant hemisphere $\times$ age interaction effects for volume $\left(F_{(124,46)}=\right.$ $0.885 ; p=0.706)$, thickness $\left(F_{(124,46)}=1.269 ; p=0.179\right)$, or surface area $\left(F_{(124,46)}=1.092 ; p=0.375\right)$. Thus, the sum of rightand left-hemisphere volumes was used in all analyses. As expected, males had larger TBVs than females as evidenced by an 
Table 3. Results from regression analyses with raw volumes

\begin{tabular}{|c|c|c|c|c|c|c|c|c|}
\hline & \multicolumn{4}{|c|}{ Regression with age } & \multicolumn{4}{|c|}{ Regression with age and age ${ }^{2}$} \\
\hline & $\beta$ & $F$ & $p$ & $R^{2}$ & $F$ & $p$ & $R^{2}$ & $p$ age $^{2 a}$ \\
\hline Cerebral cortex & -0.60 & 95.42 & $3.78 \mathrm{E}-18$ & 0.36 & 51.91 & 2.79E-18 & 0.38 & 0.018 \\
\hline Cerebral WM & 0.41 & 34.93 & $1.84 \mathrm{E}-8$ & 0.17 & 20.84 & $8.25 E-9$ & 0.20 & 0.018 \\
\hline Hippocampus & 0.12 & 2.35 & 0.127 & 0.01 & 3.11 & 0.047 & 0.04 & 0.052 \\
\hline Amygdala & 0.16 & 4.32 & 0.039 & 0.03 & 3.97 & 0.021 & 0.05 & 0.061 \\
\hline Caudate & -0.21 & 8.13 & 0.005 & 0.05 & 4.56 & 0.012 & 0.05 & 0.324 \\
\hline Putamen & -0.38 & 28.12 & $3.54 \mathrm{E}-7$ & 0.14 & 13.98 & $2.43 \mathrm{E}-6$ & 0.14 & 0.956 \\
\hline Pallidum & -0.32 & 18.66 & $2.65 \mathrm{E}-5$ & 0.10 & 9.42 & $1.33 \mathrm{E}-4$ & 0.10 & 0.612 \\
\hline Accumbens & -0.30 & 16.90 & $6.15 \mathrm{E}-5$ & 0.09 & 9.88 & $8.82 \mathrm{E}-5$ & 0.11 & 0.103 \\
\hline Thalamus & -0.02 & 0.04 & 0.849 & $2.16 \mathrm{E}-4$ & 0.08 & 0.925 & 0.001 & 0.731 \\
\hline Cerebellum GM & -0.26 & 11.89 & 0.001 & 0.07 & 7.01 & 0.001 & 0.08 & 0.154 \\
\hline Cerebellum WM & 0.35 & 23.48 & $2.84 \mathrm{E}-6$ & 0.12 & 18.37 & $6.12 \mathrm{E}-8$ & 0.18 & 0.001 \\
\hline Brainstem & 0.37 & 26.55 & $7.09 \mathrm{E}-7$ & 0.14 & 17.67 & $1.08 \mathrm{E}-7$ & 0.17 & 0.006 \\
\hline Lateral ventricle & 0.34 & 21.56 & $6.87 \mathrm{E}-6$ & 0.11 & 10.99 & $3.28 \mathrm{E}-5$ & 0.12 & 0.489 \\
\hline Inferior lateral ventricle & -0.07 & 0.94 & 0.335 & 0.01 & 0.47 & 0.628 & 0.01 & 0.955 \\
\hline Third ventricle & 0.09 & 1.38 & 0.241 & 0.01 & 1.76 & 0.176 & 0.02 & 0.147 \\
\hline Fourth ventricle & $-9.52 \mathrm{E}-4$ & $1.53 \mathrm{E}-4$ & 0.990 & $9.06 \mathrm{E}-7$ & 0.01 & 0.988 & $1.38 \mathrm{E}-4$ & 0.880 \\
\hline
\end{tabular}

Results shown are from two separate regression analyses with raw volumes, one with only age as the predictor variable and the other with both age and age ${ }^{2}$ as predictor variables. Bold characters for $R^{2}$ indicate a statistically significant quadratic age relationship.

${ }^{a}$ The $p$ value for the unique contribution of age ${ }^{2}$ to the explained variance in brain volume.

Table 4. Results from regression analyses with TBV-corrected volumes

\begin{tabular}{|c|c|c|c|c|c|c|c|c|}
\hline & \multicolumn{4}{|c|}{ Regression with age } & \multicolumn{4}{|c|}{ Regression with age and age ${ }^{2}$} \\
\hline & $\beta$ & $F$ & $p$ & $R^{2}$ & $F$ & $p$ & $R^{2}$ & $p$ age $^{2 a}$ \\
\hline Cortex volume & -0.83 & 384.98 & $1.98 \mathrm{E}-45$ & 0.70 & 276.27 & $7.64 \mathrm{E}-54$ & 0.77 & $1.94 \mathrm{E}-11$ \\
\hline Cerebral WM & 0.82 & 356.03 & $1.87 \mathrm{E}-43$ & 0.68 & 230.68 & $6.59 \mathrm{E}-49$ & 0.73 & $2.15 E-8$ \\
\hline Hippocampus & 0.24 & 9.85 & 0.002 & 0.06 & 7.62 & $6.81 \mathrm{E}-4$ & 0.08 & 0.025 \\
\hline Amygdala & 0.34 & 21.64 & $6.62 \mathrm{E}-6$ & 0.11 & 14.18 & $2.05 \mathrm{E}-6$ & 0.14 & 0.015 \\
\hline Caudate & -0.20 & 6.74 & 0.010 & 0.04 & 4.26 & 0.016 & 0.05 & 0.188 \\
\hline Putamen & -0.41 & 34.55 & $2.16 \mathrm{E}-8$ & 0.17 & 17.23 & $1.56 \mathrm{E}-7$ & 0.17 & 0.754 \\
\hline Pallidum & -0.33 & 20.03 & $1.40 \mathrm{E}-5$ & 0.11 & 10.00 & $7.87 \mathrm{E}-5$ & 0.11 & 0.773 \\
\hline Accumbens & -0.31 & 17.44 & $4.75 E-5$ & 0.09 & 10.20 & $6.60 \mathrm{E}-5$ & 0.11 & 0.097 \\
\hline Thalamus & 0.10 & 1.83 & 0.177 & 0.01 & 0.91 & 0.403 & 0.01 & 0.963 \\
\hline Cerebellum GM & -0.27 & 13.03 & $4.04 \mathrm{E}-4$ & 0.07 & 7.73 & 0.001 & 0.08 & 0.13 \\
\hline Cerebellum WM & 0.45 & 41.66 & $1.10 \mathrm{E}-9$ & 0.20 & 29.86 & $8.03 \mathrm{E}-12$ & 0.26 & $1.79 \mathrm{E}-4$ \\
\hline Brainstem & 0.55 & 72.68 & $8.21 \mathrm{E}-15$ & 0.30 & 45.43 & $1.70 \mathrm{E}-16$ & 0.35 & $4.09 \mathrm{E}-4$ \\
\hline Lateral ventricle & 0.38 & 28.09 & $3.58 \mathrm{E}-7$ & 0.14 & 14.42 & $1.67 \mathrm{E}-6$ & 0.15 & 0.379 \\
\hline Inferior lateral ventricle & -0.07 & 0.82 & 0.367 & 0.01 & 0.410 & 0.664 & 0.01 & 0.936 \\
\hline Third ventricle & 0.14 & 3.31 & 0.071 & 0.02 & 3.33 & 0.038 & 0.04 & 0.070 \\
\hline Fourth ventricle & 0.02 & 0.07 & 0.796 & $3.96 \mathrm{E}-4$ & 0.07 & 0.934 & 0.001 & 0.793 \\
\hline
\end{tabular}

Results shown are from two separate regression analyses with TBV-corrected volumes, one with only age as the predictor variable and the other with both age and age ${ }^{2}$ as predictor variables. Bold characters for $R^{2}$ indicate a statistically significant quadratic age relationship.

${ }^{a}$ The $p$ value for the unique contribution of age ${ }^{2}$ to the explained variance in brain volume.

independent-samples $t$ test (males: $1,290,900 \mathrm{~mm}^{3}$; SD, 87,897; females: $1,152,300 \mathrm{~mm}^{3}$; SD, 80,731; $t_{(169)}=-10.75 ; p=$ $0.0001)$. Also, as can be seen from Table 2 , the variance was high within the age groups. Analysis of covariance with 16 TBVcorrected brain volumes as the within-subjects factor, sex as the between-subjects factor, and age as a covariate showed no sex $\times$ age interaction effects $\left(F_{(22,23)}=0.68 ; p=0.82\right)$ or sex $\times$ age $\times$ structure effects $\left(F_{(182.737,191.043)}=1.141 ; p=0.183\right)$. This analysis was also performed with the regional cortical variables, revealing no significant sex $X$ age effects in thickness $\left(F_{(22,23)}=0.876 ; p=0.743\right)$, surface area $\left(F_{(22,23)}=0.867 ; p=\right.$ $0.630)$, or TBV-corrected volumes $\left(F_{(22,23)}=0.852 ; p=0.645\right)$ or sex $\times$ age $X$ structure effects for thickness $\left(F_{(53.864,56.312)}=0.963\right.$; $p=0.554)$, surface area $\left(F_{(44.832,46.869)}=0.823 ; p=743\right)$, or TBV-corrected volumes $\left(F_{(42.731,44.673)}=0.881 ; p=0.660\right)$. There may still be sex effects of interest in select structures. However, since no interaction effect of sex and age was shown in this overall analysis, and sex is not the primary focus of the present study, additional analyses were performed on males and females together.
Relationships between age and brain volumes

The volume for each brain structure in each of five age groups is displayed in Table 2. The volume, thickness, and surface area of each cortical lobe and total cerebral cortex are displayed in supplemental Table 1 (available at www.jneurosci.org as supplemental material). The results of the regression analyses with subcortical brain volumes are shown in Tables 3 and 4, whereas Table 5 shows the results of the regression analyses with cortical variables (volume, thickness, and surface area). In the raw volume analyses, all GM volumes, except hippocampus, amygdala, and thalamus, showed a negative relationship with age $(p<$ 0.05). Amygdala and hippocampus showed a slight positive relationship with age, but only the amygdala increase was significant. The cerebral cortex was the only GM structure that showed a curvilinear relationship with age. This pattern was seen in the parietal and occipital lobe volumes in the regional cortical analysis, whereas the frontal and temporal lobes were best described by linear age relationships. In the cortical thickness analysis, the frontal, parietal, and occipital lobes showed quadratic age relationships, and the temporal lobe showed a linear age relationship. 
Table 5. Regression analyses with cortical lobe volumes, thickness, and surface area

\begin{tabular}{|c|c|c|c|c|c|c|c|c|}
\hline & \multicolumn{4}{|c|}{ Regression with age } & \multicolumn{4}{|c|}{ Regression with age and age ${ }^{2}$} \\
\hline & $\beta$ & $F$ & $p$ & $R^{2}$ & $F$ & $p$ & $R^{2}$ & $p \operatorname{age}^{2 a}$ \\
\hline \multicolumn{9}{|l|}{ Volume } \\
\hline Total cortex & -0.83 & 384.98 & $1.98 \mathrm{E}-45$ & 0.36 & 276.27 & $7.64 \mathrm{E}-54$ & 0.38 & $1.94 \mathrm{E}-11$ \\
\hline Frontal & -0.58 & 85.14 & $1.12 \mathrm{E}-16$ & 0.34 & 43.42 & $6.29 \mathrm{E}-16$ & 0.34 & 0.227 \\
\hline Parietal & -0.67 & 135.72 & $2.12 \mathrm{E}-23$ & 0.45 & 87.36 & $9.81 \mathrm{E}-27$ & 0.51 & 5.43E-06 \\
\hline Temporal & -0.41 & 34.86 & $1.89 \mathrm{E}-08$ & 0.17 & 17.69 & $1.07 \mathrm{E}-07$ & 0.17 & 0.442 \\
\hline Occipital & -49 & 54.47 & $6.83 \mathrm{E}-12$ & 0.24 & 32.34 & $1.31 \mathrm{E}-12$ & 0.28 & 0.005 \\
\hline \multicolumn{9}{|c|}{ TBV-corrected volume } \\
\hline Total cortex & -0.83 & 384.98 & $1.98 \mathrm{E}-45$ & 0.70 & 276.27 & $7.64 \mathrm{E}-54$ & 0.77 & $1.94 \mathrm{E}-11$ \\
\hline Frontal & -0.77 & 238.48 & $4.02 \mathrm{E}-34$ & 0.59 & 130.30 & $6.80 \mathrm{E}-35$ & 0.61 & 0.002 \\
\hline Parietal & -0.79 & 281.04 & $8.81 \mathrm{E}-38$ & 0.62 & 253.31 & $1.93 \mathrm{E}-51$ & 0.75 & $1.09 \mathrm{E}-16$ \\
\hline Temporal & -0.61 & 98.02 & $1.64 \mathrm{E}-18$ & 0.37 & 53.37 & $1.14 \mathrm{E}-18$ & 0.39 & 0.016 \\
\hline Occipital & -0.55 & 72.65 & $8.31 \mathrm{E}-15$ & 0.30 & 48.41 & $2.51 \mathrm{E}-17$ & 0.37 & 5.33E-05 \\
\hline \multicolumn{9}{|l|}{ Thickness } \\
\hline Total cortex & -0.81 & 314.81 & $1.91 \mathrm{E}-40$ & 0.65 & 181.89 & $9.22 \mathrm{E}-43 \mathrm{a}$ & 0.68 & $4.09 \mathrm{E}-5$ \\
\hline Frontal & -0.76 & 233.44 & 1.16E-33 & 0.58 & 129.26 & $1.03 \mathrm{E}-34$ & 0.61 & 0.001 \\
\hline Parietal & -0.82 & 345.42 & $2.42 \mathrm{E}-43$ & 0.68 & 225.70 & $2.52 \mathrm{E}-48$ & 0.73 & $6.54 \mathrm{E}-8$ \\
\hline Temporal & -0.53 & 66.10 & 8.74E-14 & 0.28 & 33.62 & $5.24 \mathrm{E}-13$ & 0.29 & 0.297 \\
\hline Occipital & -0.77 & 239.56 & $3.21 \mathrm{E}-34$ & 0.59 & 157.29 & $3.21 \mathrm{E}-39$ & 0.65 & $7.68 \mathrm{E}-8$ \\
\hline \multicolumn{9}{|l|}{ Surface area } \\
\hline Total cortex & -0.32 & 18.80 & $2.49 \mathrm{E}-5$ & 0.10 & 10.23 & $6.42 \mathrm{E}-5$ & 0.11 & 0.208 \\
\hline Frontal & -0.33 & 21.18 & $8.18 \mathrm{E}-6$ & 0.11 & 10.76 & $4.02 \mathrm{E}-5$ & 0.11 & 0.525 \\
\hline Parietal & -0.35 & 24.27 & $1.98 \mathrm{E}-6$ & 0.13 & 16.40 & $3.12 \mathrm{E}-7$ & 0.16 & 0.007 \\
\hline Temporal & -0.22 & 8.34 & 0.004 & 0.05 & 4.20 & 0.017 & 0.05 & 0.759 \\
\hline Occipital & -0.18 & 5.73 & 0.018 & 0.03 & 3.64 & 0.028 & 0.04 & 0.218 \\
\hline
\end{tabular}

Results shown are from two separate regression analyses with both raw and TBV-corrected lobar volumes, thickness, and surface area, one with only age as the predictor variable and the other with both age and age ${ }^{2}$ as predictor variables. Bold characters for $R^{2}$ indicate a statistically significant quadratic age relationship.

${ }^{a}$ The $p$ value for the unique contribution of age ${ }^{2}$ to the explained variance in brain volume.

All lobar surface areas showed statistically significant age relationships, and the parietal lobe surface area also showed a quadratic relationship with age $(p<0.05)$. All WM volumes (cerebral WM, cerebellar WM, brainstem) showed a quadratic relationship with age $(p<0.05)$. The lateral ventricles increased linearly with age, whereas the inferior lateral ventricles and the third and fourth ventricles showed no significant relationship with age. With Bonferroni corrections, the amygdala and caudate age relationships no longer reached significance in the volumetric analysis, whereas the additional contribution of age ${ }^{2}$ to the explained variance in the parietal surface area disappeared. When introducing age ${ }^{3}$ as a third regressor, an additional unique variance $(p<0.05)$ was explained in only one structure, the pallidum, for which $R^{2}$ increased from 0.10 to 0.13 ( $p=0.02$ ) (not displayed in the tables). The regression plots for the raw volumes are displayed in supplemental Figure 1 (available at www.jneurosci. org as supplemental material). The regression plots for the regional cortical variables (thickness and surface area) are displayed in Figure 3.

When the analyses were repeated with the TBV-corrected volumes as the dependent variables (Tables 4,5 ), the finding that most GM volumes decreased with age while the WM volumes increased was replicated. However, hippocampus showed a significant positive relationship with age, and both the hippocampus and the amygdala showed a nonlinear increase in volume. The regional cortical analysis revealed statistically significant contributions of age ${ }^{2}$ in all four cortical lobes. As in the analyses with the raw volumes, an additional unique variance $(p<0.05)$ was explained in only the pallidum when introducing age ${ }^{3}$ as a third regressor, with $R^{2}$ increasing from 0.11 to 0.13 ( $p=0.048$ ) (not displayed in the tables). The amount of variance explained by age tended to increase for the cerebral cortex and WM, cerebellum WM, brainstem, amygdala, putamen, lateral ventricles, and hippocampus when TBV-corrected volumes were analyzed compared with the raw volumes. When the results were Bonferroni corrected, the TBV-corrected caudate age relationship no longer reached statistical significance, and the contribution of age $^{2}$ to hippocampus, amygdala, and temporal lobe also disappeared, as did the cubic component in the regression with pallidum. Regression analyses were also performed with TBV, age, and age $^{2}$ in the model, to enable evaluation of these separate components, and the results are shown supplemental Table 2 (available at www.jneurosci.org as supplemental material). Generally, TBV showed a profound effect on individual brain variables. The TBV-corrected cerebral cortex (frontal and parietal lobes more than temporal and occipital lobes), cerebral WM, brainstem, cerebellar WM, and amygdala showed the greatest impact of age in terms of explained variance, whereas the hippocampus, the cerebellum cortex, and the caudate showed the least impact of age in this analysis. The regression plots for TBVcorrected GM and WM volumes and ventricles are displayed in Figures 1 and 2. The regression plots for the TBV-corrected regional cortical volumes are displayed in Figure 3.

The results of the regression analyses with proportional volumes of TBV are displayed in supplemental Table 3 (available at www.jneurosci.org as supplemental material), and the results primarily mirrored the results of the regressions with the standardized residuals after correcting for TBV. Additional analyses were therefore not performed with the proportional measures as dependent variables. The regression plots for proportional volumes are shown in supplemental Figure 2 (available at www. jneurosci.org as supplemental material).

\section{Characteristics of the rate of change of nonlinearly developing structures}

When age ${ }^{2}$ was a significant predictor independent of age, nonlinear regression analyses were run. Relative differential nonlinear trajectories were found for the cerebral cortex, cerebral WM, 
brainstem, and cerebellum WM in the raw volume analyses, and additionally for the amygdala and hippocampus in the analysis with the TBV-corrected volumes. The time constant values are shown in Table 6. Cerebellar WM, amygdala, and hippocampus appeared to undergo a relatively rapid change early in the studied age span, whereas the cerebral WM, cerebral cortex, and brainstem showed less steep changes in the earliest part of the age span. Within the cerebral cortex, the frontal and temporal lobes appeared to approach the peak in volume reduction later than the parietal and occipital lobes, as seen in Table 7. Time constant estimates were derived from the exponential fitting analysis of frontal, parietal, and occipital thickness, showing earlier thinning in the occipital lobes. Only the parietal lobe surface area showed a nonlinear age relationship, making it difficult to compare the time constant estimate with the trajectories of the remaining lobar areas.

Estimated percentage change

From the raw volumes, percentage change from 8 to 30 years was estimated, and the results are shown in Table 6. For the structures with nonlinear age relationships, the nonlinear analysis equation was used to estimate the percentage change. The lateral ventricular volume changed the most, with a near $100 \%$ increase during this age range. Also, the WM volumes (in cerebrum, cerebellum, and brainstem) showed high percentage increases in volume. As can be seen in Figure 3, the cerebral cortex, followed by the putamen, accumbens, and pallidum, showed the greatest percentage decrease, whereas the amygdala, hippocampus, and thalamus were the structures that appeared to change the least from 8 to 30 years of age. Within the cerebral cortex, thickness changed by $8.3-19.4 \%$, with the greatest change in parietal and occipital lobes. Surface area changed by $7.0-20.9 \%$, with the greatest change observed in the frontal lobes, whereas lobar volumes changed $15.0-28.5 \%$, with the greatest change observed in parietal lobes, as seen in Table 7.

Differential age relationships within subcortical regions

To explore whether differential age relationships between adjacent subcortical structures can be observed, statistical comparisons were made within the basal ganglia and within the temporal lobe subcortical structures. Within the basal ganglia, the putamen showed a stronger relationship with age than the caudate (TBV-corrected volumes), as there was a significant difference between the age correlations of -0.19 for the caudate and -0.40 for the putamen $\left(t_{(168)}=2.37 ; p<0.05\right)$. The difference in age correlations between the caudate and the pallidum $(-0.31)$ was not significant $\left(t_{(168)}=1.56 ; p>0.05\right)$. There was no significant difference between the age correla-
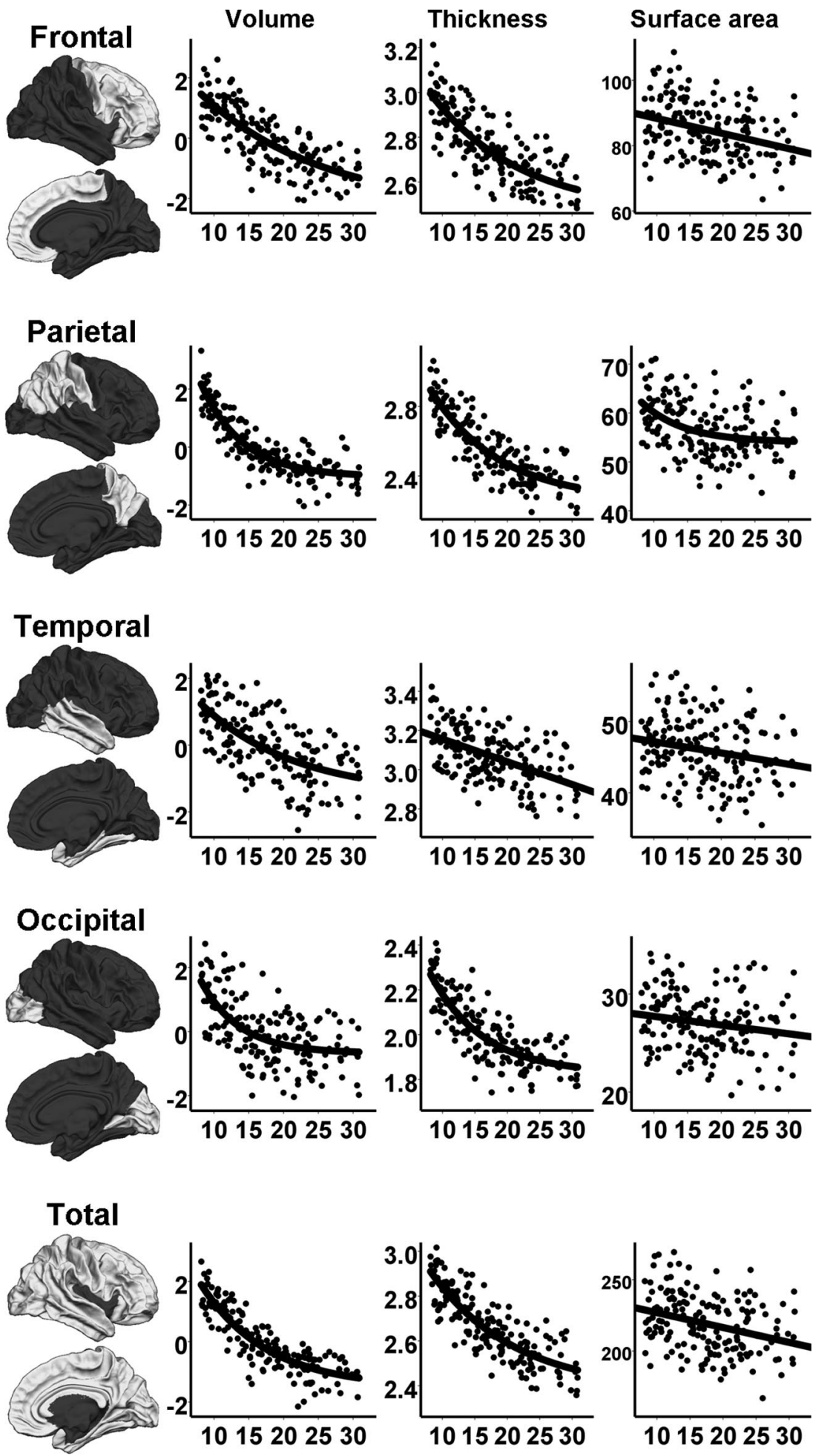

Figure 3. Regression plots showing the relationship between age and bilateral cortical volume (TBV corrected), thickness, and surface area for each cortical lobe and for the total cerebral cortex, with age on the horizontal axes. The measurements are standardized residuals (volumes), in millimeters (thickness), and in square millimeters (surface area) on the vertical axes. The parcellation of the cortical lobes are displayed in the left column.

tion of 0.26 for the hippocampus and 0.36 for the amygdala $\left(t_{(168)}=1.29 ; p>0.05\right)$.

\section{Discussion}

The results of the present study confirmed the general notion that GM decreases while WM and lateral ventricular volumes increase 
Table 6. Age effects in terms of explained variance $\left(R^{2}\right)$, time constant $(t)$, absolute change, and percentage change

\begin{tabular}{|c|c|c|c|c|c|c|}
\hline & \multicolumn{2}{|c|}{ TBV-corrected volumes } & \multicolumn{4}{|c|}{ Raw volumes } \\
\hline & $R^{2}$ & $t$ & $R^{2}$ & $t$ & Absolute change & Percentage change \\
\hline Cerebral cortex & 0.77 & 9.47 & 0.38 & 14.88 & 129,206 & -21.5 \\
\hline Cerebral WM & 0.73 & 11.06 & 0.21 & 5.33 & 103,314 & 26.1 \\
\hline Hippocampus & 0.08 & 5.51 & 0.01 & & 322 & 3.7 \\
\hline Amygdala & 0.14 & 6.42 & 0.03 & & 241 & 6.8 \\
\hline Caudate & 0.04 & & 0.05 & & 682 & -8.2 \\
\hline Putamen & 0.17 & & 0.14 & & 1703 & -13.1 \\
\hline Pallidum & 0.11 & & 0.10 & & 434 & -11.4 \\
\hline Accumbens & 0.09 & & 0.09 & & 195 & -13.0 \\
\hline Thalamus & 0.01 & & $2.16 \mathrm{E}-4$ & & 63 & 0.4 \\
\hline Cerebellum GM & 0.07 & & 0.07 & & 11,047 & -8.9 \\
\hline Cerebellum WM & 0.27 & 4.54 & 0.20 & 2.87 & 6347 & 27.3 \\
\hline Brainstem & 0.35 & 7.03 & 0.19 & 3.69 & 3893 & 22.1 \\
\hline Lateral ventricle & 0.14 & & 0.11 & & 8372 & 99.8 \\
\hline Inferior lateral ventricle & 0.01 & & 0.01 & & 78 & 12.5 \\
\hline Third ventricle & 0.02 & & 0.01 & & 72 & 7.9 \\
\hline Fourth ventricle & $3.96 \mathrm{E}-4$ & & $9.06 \mathrm{E}-7$ & & 2 & 0.1 \\
\hline
\end{tabular}

$R^{2}$ is from the nonlinear regression analysis. Time constant $(t)$ indicates the rate of development, calculated from the exponential fitting equations of the form $x=b_{1}+b_{2} \times e^{(- \text {age/t } t}$, where $b_{1}$ is the estimated value at the asymptote and $b_{2}$ is the difference between the $b_{1}$ value and the estimated value at age zero. Lower values indicate a faster developmental course. When no value of $t$ is presented, a linear fit best described the data, and $R^{2}$ is from the linear regression. Absolute and percentage change is calculated from the estimated mean values for 8 year olds and 30 year olds.

Table 7. Age effects in terms of explained variance $\left(R^{2}\right)$, time constant $(t)$, absolute change, and percentage change in cortical volume, thickness, and surface area

\begin{tabular}{|c|c|c|c|c|c|c|}
\hline & \multicolumn{2}{|c|}{ TBV-corrected volumes } & \multicolumn{4}{|c|}{ Raw volumes/variables } \\
\hline & $R^{2}$ & $t$ & $R^{2}$ & $t$ & Absolute change & Percentage change \\
\hline Cortex volume & 0.77 & 9.47 & 0.38 & 14.88 & 129,206 & -21.5 \\
\hline Frontal volume & 0.61 & 17.72 & 0.34 & & 46,196 & -20.0 \\
\hline Parietal volume & 0.76 & 6.00 & 0.51 & 8.29 & 46,550 & -28.5 \\
\hline Temporal volume & 0.39 & 13.57 & 0.17 & & 20,170 & -15.0 \\
\hline Occipital volume & 0.38 & 5.57 & 0.28 & 8.34 & 14,901 & -23.0 \\
\hline Mean thickness & & & 0.69 & 12.93 & 0.44 & -15.1 \\
\hline Frontal thickness & & & 0.61 & 14.08 & 0.43 & -14.3 \\
\hline Parietal thickness & & & 0.73 & 10.72 & 0.56 & -19.4 \\
\hline Temporal thickness & & & 0.28 & & 0.26 & -8.3 \\
\hline Occipital thickness & & & 0.66 & 8.14 & 0.42 & -18.4 \\
\hline Cortex area & & & 0.10 & & 22,898 & -10.0 \\
\hline Frontal area & & & 0.11 & & 18,642 & -20.9 \\
\hline Parietal area & & & 0.16 & 6.30 & 5595 & -9.4 \\
\hline Temporal area & & & 0.05 & & 3486 & -7.3 \\
\hline Occipital area & & & 0.03 & & 1965 & -7.0 \\
\hline
\end{tabular}

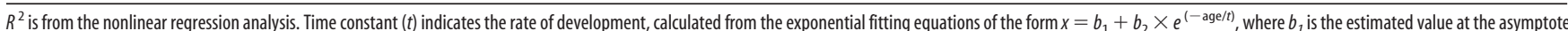
and $b_{2}$ is the difference between the $b_{1}$ value and the estimated value at age zero. Lower values indicate a faster developmental course. When no value of $t$ is presented, a linear fit best described the data, and $R^{2}$ is from the linear regression. Absolute and percentage change is calculated from the estimated mean values for 8 year olds and 30 year olds.

during late childhood and adolescence (Jernigan et al., 1991; Giedd et al., 1996b, 1999; Reiss et al., 1996; Sowell et al., 1999, 2002; Gogtay et al., 2004; Lenroot et al., 2007; Shaw et al., 2008), while simultaneously pointing to important nuances in subcortical development. Volume reductions were not observed in all GM structures; there were no age effects on thalamic volume, and the hippocampus and amygdala showed volume increases. Overall, the results were characterized by substantial heterogeneity. Unless specified otherwise, the remainder of the discussion will deal with the results of the TBV-corrected analyses.

\section{Heterogeneous age effects}

The reduction in cortical volume was driven by both a reduction in thickness and a slight reduction in surface area, seen in all lobar regions. The cerebral cortex, and the cortical lobe volumes, differed from subcortical GM volumes by showing a stronger relationship with age $(37-77 \%$ vs $4-16 \%$ explained variance of age; $15-28.5 \%$ vs $3-13 \%$ change from 8 to 30 years) and by showing a nonlinear relationship with age, whereas linear age relationships were found in most subcortical structures. Proportionally stronger age effects in frontal cortical GM compared with subcortical structures have also been reported by Sowell et al. (2002). Lobar cortical thickness was characterized by strong age effects but less percentage change than cortical volumes [see Tamnes et al. (2009) for voxel-wise and regional thickness analyses]. Cortical surface area showed less developmental effects, comparable to effects seen for subcortical raw and TBVcorrected volumes. Differential properties of thickness and surface area have also been pointed out by Panizzon et al. (2009) using an adult sample.

WM volumes changed more than cortical and subcortical GM, which is in line with previous literature (Sowell et al., 2002), up to $27 \%$. All WM volumes showed decelerating nonlinear increases during development. However, different rates of development were revealed by looking at the time constants from the nonlinear regression analyses. The increase in WM volume of the brainstem and cerebellum approached the asymptote earlier than what was the case for cerebral WM. 


\section{Basal ganglia and the accumbens area}

Basal ganglia structures and the accumbens area showed similarities in development as they all were moderately and linearly related to age. These structures changed relatively little compared with cortical and frontal cortical GM. Sowell et al. (2002) have previously pointed out the similarities in development between different basal ganglia structures. However, the differences may also be noteworthy, as there has been a focus on only the caudate in many reports (Lenroot et al., 2007; Wilke et al., 2007; Giedd, 2008), and few studies, with the exception of Sowell et al. (2002) and Jernigan et al. (1991), have tried to disentangle maturational effects on different parts of the basal ganglia. In the present study, the caudate showed the weakest relationship with age (nonsignificant with Bonferroni correction) and changed the least compared with lenticular nuclei. The statistical analyses of the basal ganglia structures' different relationships with age also confirmed this point. This seems to be in line with previous reports in which both the caudate and lenticular nuclei have been studied in the same sample (Jernigan et al., 1991; Sowell et al., 2002).

\section{Cerebellum}

Differential developmental properties were also discovered for GM and WM within the cerebellum. A general cerebellar volume increase has been observed (Sowell et al., 2002; Mackie et al., 2007), along with a nonlinear decrease in cerebellar GM volume (Mackie et al., 2007). Our results confirmed a general tendency of cerebellar GM reduction, although linear. Giedd et al. (2007) commented on the cerebellum as being among the latest structures to reach peak volume. Interestingly, our cerebellar WM analysis indicates an early development, as the time constant derived from the nonlinear equation was low, especially compared with cerebral WM. Although our data could not pinpoint the exact timing of cerebellar GM development (because of the linear fitting of data), the results for cerebellar WM indicate differential developmental trajectories in GM and WM in the cerebellum. This needs to be confirmed by future studies.

\section{Temporal lobe subcortical GM}

Hippocampus and amygdala diverge from the other GM volumes in their slight increase with age during development. Our data are in line with some of the previous studies and reviews (Giedd et al., 1996b; Toga et al., 2006; Guo et al., 2007), but discrepancies exist (Giedd et al., 1996b; Sowell et al., 2002; Gogtay et al., 2006). It must be noted that the observed age effect in the hippocampus was weak, appearing only when correcting for TBV (without Bonferroni correction), although a tendency was also visible for the raw volumes. Gogtay et al. (2006) argued that the weak and diverging developmental effects in the hippocampus may be attributable to opposing effects in subregions of the hippocampus. However, the relatively more robust effect in the nearby amygdala supports the finding of a volume increase. Caution must be taken, as the contribution of age ${ }^{2}$ to these two volumes did not reach statistical significance when correcting for multiple comparisons.

\section{GM reduction and WM increase in light of developmental principles}

Myelination has been shown to constitute a major developmental principle during late childhood and through adolescence, supported by recent diffusion tensor imaging studies (Giedd et al., 1999; Paus et al., 2001; Sowell et al., 2002; Giedd, 2004; Barnea-Goraly et al., 2005; Ashtari et al., 2007; Giorgio et al., 2008; Lebel et al., 2008). GM reduction is thought to, in part, reflect synaptic pruning (Huttenlocher, 1990). However, it is also possible that GM reductions are attributable to increased myelination, pushing the border between segmented GM and WM in favor of WM volume (Sowell et al., 2004; Shaw et al., 2008). This would likely be the case also for subcortical structures, surrounded by myelinated, long-distance axonal projections of neurons. The temporal lobe structures show a different developmental pattern than the other GM structures, making it possible that other neurobiological mechanisms are responsible for the maturational changes observed. Although the present results do not directly explain neurobiological mechanisms in development, the pattern of increases and decreases observed here represents valuable developmental information and points to the need for a better understanding of the biological mechanisms in brain development.

These developmental principles must be considered together with cognitive development, to disentangle the relationships between the dynamics of volumetric changes and cognitive performance throughout childhood and adolescence. The nonlinear and dynamic nature of brain development makes this especially important, as the differential trajectories may have different cognitive implications. For instance, there is some evidence from functional MRI studies to suggest that subcortical structures and cortical areas may play different roles at different times during cognitive development (Menon et al., 2005; Ciesielski et al., 2006; Galvan et al., 2006). However, it remains elusive how this relates to differential regional structural neurodevelopment.

\section{Limitations and conclusions}

Future investigations are needed to confirm the results in a longitudinal design. This has the advantage of being more sensitive to individual differences in developmental trajectories, thus potentially capturing developmental peaks early in the age span, as has been found by Giedd et al. (1999). Studying children and adults in the same sample also raises some methodological problems. For instance, the scans of younger children may be more prone to movement artifacts, which could lead to erroneous estimations of brain measures. Our data were characterized by a greater reliance on only one scan among the younger participants. However, negligible differences have been found between using one versus two averaged scans (Han et al., 2006). Children may have smaller neuroanatomical volumes, and hence biases may be introduced when comparing neuroanatomical segmentations across children and adults. For instance, child scan segmentations may suffer from greater partial volume effects. However, the TBV of 8 year olds is probably comparable to that of adults (Reiss et al., 1996), and the classification technique used employs a registration procedure that is especially well suited to account for varying anatomies (Fischl et al., 2004). Also, by visual inspection of the segmentations, the techniques used were deemed to yield accurate results in children of the present age. Another limitation of the present study is that brain development was only studied from 8 years of age and up. Clearly, dramatic changes take place much earlier in development (Giedd et al., 1996a; Gogtay et al., 2004; Gogtay et al., 2006; Knickmeyer et al., 2008). Still, our cross-sectional data from the present age range yielded results that shed new light on brain development seen as a whole. GM decreases in cerebral cortex, basal ganglia/accumbens, and cerebellum were confirmed, as were GM increases in hippocampus and amygdala and WM and ventricular increases. Especially noteworthy are the nuances in developmental differences observed, as shown by the differential age effects within the basal ganglia, between cortex and subcortical structures, and the 
patterns of cerebellar WM development compared with both cerebellar GM and cerebral WM.

\section{References}

Ashtari M, Cervellione KL, Hasan KM, Wu J, McIlree C, Kester H, Ardekani BA, Roofeh D, Szeszko PR, Kumra S (2007) White matter development during late adolescence in healthy males: a cross-sectional diffusion tensor imaging study. Neuroimage 35:501-510.

Barnea-Goraly N, Menon V, Eckert M, Tamm L, Bammer R, Karchemskiy A, Dant CC, Reiss AL (2005) White matter development during childhood and adolescence: a cross-sectional diffusion tensor imaging study. Cereb Cortex 15:1848-1854.

Ciesielski KT, Lesnik PG, Savoy RL, Grant EP, Ahlfors SP (2006) Developmental neural networks in children performing a Categorical N-Back Task. Neuroimage 33:980-990.

Dale AM, Fischl B, Sereno MI (1999) Cortical surface-based analysis. I. Segmentation and surface reconstruction. Neuroimage 9:179-194.

Desikan RS, Segonne F, Fischl B, Quinn BT, Dickerson BC, Blacker D, Buckner RL, Dale AM, Maguire RP, Hyman BT, Albert MS, Killiany RJ (2006) An automated labeling system for subdividing the human cerebral cortex on MRI scans into gyral based regions of interest. Neuroimage 31:968-980.

Dickerson BC, Fenstermacher E, Salat DH, Wolk DA, Maguire RP, Desikan R, Pacheco J, Quinn BT, Van der Kouwe A, Greve DN, Blacker D, Albert MS, Killiany RJ, Fischl B (2008) Detection of cortical thickness correlates of cognitive performance: reliability across MRI scan sessions, scanners, and field strengths. Neuroimage 39:10-18.

Fischl B, Dale AM (2000) Measuring the thickness of the human cerebral cortex from magnetic resonance images. Proc Natl Acad Sci U S A 97:11050-11055.

Fischl B, Sereno MI, Dale AM (1999a) Cortical surface-based analysis. II: Inflation, flattening, and a surface-based coordinate system. Neuroimage 9:195-207.

Fischl B, Sereno MI, Tootell RB, Dale AM (1999b) High-resolution intersubject averaging and a coordinate system for the cortical surface. Hum Brain Mapp 8:272-284.

Fischl B, Liu A, Dale AM (2001) Automated manifold surgery: constructing geometrically accurate and topologically correct models of the human cerebral cortex. IEEE Trans Med Imaging 20:70-80.

Fischl B, Salat DH, Busa E, Albert M, Dieterich M, Haselgrove C, van der Kouwe A, Killiany R, Kennedy D, Klaveness S, Montillo A, Makris N, Rosen B, Dale AM (2002) Whole brain segmentation: automated labeling of neuroanatomical structures in the human brain. Neuron 33:341-355.

Fischl B, Salat DH, van der Kouwe AJ, Makris N, Segonne F, Quinn BT, Dale AM (2004) Sequence-independent segmentation of magnetic resonance images. Neuroimage 23 [Suppl 1]:S69-S84.

Galvan A, Hare TA, Parra CE, Penn J, Voss H, Glover G, Casey BJ (2006) Earlier development of the accumbens relative to orbitofrontal cortex might underlie risk-taking behavior in adolescents. J Neurosci 26:6885-6892.

Giedd JN (2004) Structural magnetic resonance imaging of the adolescent brain. Ann N Y Acad Sci 1021:77-85.

Giedd JN (2008) The teen brain: insights from neuroimaging. J Adolesc Health 42:335-343.

Giedd JN, Vaituzis AC, Hamburger SD, Lange N, Rajapakse JC, Kaysen D, Vauss YC, Rapoport JL (1996a) Quantitative MRI of the temporal lobe, amygdala, and hippocampus in normal human development: ages 4-18 years. J Comp Neurol 366:223-230.

Giedd JN, Snell JW, Lange N, Rajapakse JC, Casey BJ, Kozuch PL, Vaituzis AC, Vauss YC, Hamburger SD, Kaysen D, Rapoport JL (1996b) Quantitative magnetic resonance imaging of human brain development: ages 4-18. Cereb Cortex 6:551-560.

Giedd JN, Castellanos FX, Rajapakse JC, Vaituzis AC, Rapoport JL (1997) Sexual dimorphism of the developing human brain. Prog Neuropsychopharmacol Biol Psychiatry 21:1185-1201.

Giedd JN, Blumenthal J, Jeffries NO, Castellanos FX, Liu H, Zijdenbos A, Paus T, Evans AC, Rapoport JL (1999) Brain development during childhood and adolescence: a longitudinal MRI study. Nat Neurosci 2:861-863.

Giedd JN, Schmitt JE, Neale MC (2007) Structural brain magnetic resonance imaging of pediatric twins. Hum Brain Mapp 28:474-481.

Giorgio A, Watkins KE, Douaud G, James AC, James S, De Stefano N,
Matthews PM, Smith SM, Johansen-Berg H (2008) Changes in white matter microstructure during adolescence. Neuroimage 39:52-61.

Gogtay N, Giedd JN, Lusk L, Hayashi KM, Greenstein D, Vaituzis AC, Nugent TF, 3rd, Herman DH, Clasen LS, Toga AW, Rapoport JL, Thompson PM (2004) Dynamic mapping of human cortical development during childhood through early adulthood. Proc Natl Acad Sci U S A 101:8174-8179.

Gogtay N, Nugent TF, 3rd, Herman DH, Ordonez A, Greenstein D, Hayashi KM, Clasen L, Toga AW, Giedd JN, Rapoport JL, Thompson PM (2006) Dynamic mapping of normal human hippocampal development. Hippocampus 16:664-672.

Guo X, Chen C, Chen K, Jin Z, Peng D, Yao L (2007) Brain development in Chinese children and adolescents: a structural MRI study. Neuroreport 18:875-880.

Han X, Jovicich J, Salat D, van der Kouwe A, Quinn B, Czanner S, Busa E, Pacheco J, Albert M, Killiany R, Maguire P, Rosas D, Makris N, Dale A, Dickerson B, Fischl B (2006) Reliability of MRI-derived measurements of human cerebral cortical thickness: the effects of field strength, scanner upgrade and manufacturer. Neuroimage 32:180-194.

Huttenlocher PR (1990) Morphometric study of human cerebral cortex development. Neuropsychologia 28:517-527.

Jernigan TL, Trauner DA, Hesselink JR, Tallal PA (1991) Maturation of human cerebrum observed in vivo during adolescence. Brain 114:2037-2049.

Jovicich J, Czanner S, Han X, Salat D, van der Kouwe A, Quinn B, Pacheco J, Albert M, Killiany R, Blacker D, Maguire P, Rosas D, Makris N, Gollub R, Dale A, Dickerson BC, Fischl B (2009) MRI-derived measurements of human subcortical, ventricular and intracranial brain volumes: reliability effects of scan sessions, acquisition sequences, data analyses, scanner upgrade, scanner vendors and field strengths. Neuroimage 46:177-192.

Knickmeyer RC, Gouttard S, Kang C, Evans D, Wilber K, Smith JK, Hamer RM, Lin W, Gerig G, Gilmore JH (2008) A structural MRI study of human brain development from birth to 2 years. J Neurosci 28:1217612182.

Krain AL, Castellanos FX (2006) Brain development and ADHD. Clin Psychol Rev 26:433-444.

Lebel C, Walker L, Leemans A, Phillips L, Beaulieu C (2008) Microstructural maturation of the human brain from childhood to adulthood. Neuroimage 40:1044-1055.

Lenroot RK, Gogtay N, Greenstein DK, Wells EM, Wallace GL, Clasen LS, Blumenthal JD, Lerch J, Zijdenbos AP, Evans AC, Thompson PM, Giedd JN (2007) Sexual dimorphism of brain developmental trajectories during childhood and adolescence. Neuroimage 36:1065-1073.

Liu RS, Lemieux L, Bell GS, Sisodiya SM, Shorvon SD, Sander JW, Duncan JS (2003) A longitudinal study of brain morphometrics using quantitative magnetic resonance imaging and difference image analysis. Neuroimage 20:22-33.

Mackie S, Shaw P, Lenroot R, Pierson R, Greenstein DK, Nugent TF, 3rd, Sharp WS, Giedd JN, Rapoport JL (2007) Cerebellar development and clinical outcome in attention deficit hyperactivity disorder. Am J Psychiatry 164:647-655.

Menon V, Boyett-Anderson JM, Reiss AL (2005) Maturation of medial temporal lobe response and connectivity during memory encoding. Brain Res Cogn Brain Res 25:379-385.

Panizzon MS, Fennema-Notestine C, Eyler LT, Jernigan TL, Prom-Wormley E, Neale M, Jacobson K, Lyons MJ, Grant MD, Franz CE, Xian H, Tsuang M, Fischl B, Seidman L, Dale A, Kremen WS (2009) Distinct genetic influences on cortical surface area and cortical thickness. Cereb Cortex. Advance online publication. Retrieved August 31, 2009. doi: 10.1093/cercor/bhp026.

Paus T, Collins DL, Evans AC, Leonard G, Pike B, Zijdenbos A (2001) Maturation of white matter in the human brain: a review of magnetic resonance studies. Brain Res Bull 54:255-266.

Peters M, Jancke L, Staiger JF, Schlaug G, Huang Y, Steinmetz H (1998) Unsolved problems in comparing brain sizes in Homo sapiens. Brain Cogn 37:254-285.

Reiss AL, Abrams MT, Singer HS, Ross JL, Denckla MB (1996) Brain development, gender and IQ in children. A volumetric imaging study. Brain 119:1763-1774.

Rosas HD, Liu AK, Hersch S, Glessner M, Ferrante RJ, Salat DH, van der Kouwe A, Jenkins BG, Dale AM, Fischl B (2002) Regional and progressive thinning of the cortical ribbon in Huntington's disease. Neurology 58:695-701.

Segonne F, Dale AM, Busa E, Glessner M, Salat D, Hahn HK, Fischl B (2004) 
A hybrid approach to the skull stripping problem in MRI. Neuroimage 22:1060-1075.

Shaw P, Kabani NJ, Lerch JP, Eckstrand K, Lenroot R, Gogtay N, Greenstein D, Clasen L, Evans A, Rapoport JL, Giedd JN, Wise SP (2008) Neurodevelopmental trajectories of the human cerebral cortex. J Neurosci 28:3586-3594.

Sowell ER, Thompson PM, Holmes CJ, Jernigan TL, Toga AW (1999) In vivo evidence for post-adolescent brain maturation in frontal and striatal regions. Nat Neurosci 2:859-861.

Sowell ER, Trauner DA, Gamst A, Jernigan TL (2002) Development of cortical and subcortical brain structures in childhood and adolescence: a structural MRI study. Dev Med Child Neurol 44:4-16.

Sowell ER, Thompson PM, Leonard CM, Welcome SE, Kan E, Toga AW (2004) Longitudinal mapping of cortical thickness and brain growth in normal children. J Neurosci 24:8223-8231.

Sowell ER, Peterson BS, Kan E, Woods RP, Yoshii J, Bansal R, Xu D, Zhu H, Thompson PM, Toga AW (2007) Sex differences in cortical thickness mapped in 176 healthy individuals between 7 and 87 years of age. Cereb Cortex 17:1550-1560.

Tae WS, Kim SS, Lee KU, Nam EC, Kim KW (2008) Validation of hip- pocampal volumes measured using a manual method and two automated methods (FreeSurfer and IBASPM) in chronic major depressive disorder. Neuroradiology 50:569-581.

Tamnes CK, Ostby Y, Fjell AM, Westlye LT, Due-Tonnessen P, Walhovd KB (2009) Brain maturation in adolescence and young adulthood: regional age-related changes in cortical thickness and white matter volume and microstructure. Cereb Cortex. Advance online publication. Retrieved August 31, 2009. doi: 10.1093/cercor/bhp118.

Toga AW, Thompson PM, Sowell ER (2006) Mapping brain maturation. Trends Neurosci 29:148-159.

Walhovd KB, Fjell AM, Reinvang I, Lundervold A, Dale AM, Eilertsen DE, Quinn BT, Salat D, Makris N, Fischl B (2005) Effects of age on volumes of cortex, white matter and subcortical structures. Neurobiol Aging 26: 1261-1270, discussion 1275-1268.

Wechsler D (1999) Wechsler abbreviated scale of intelligence. San Antonio, TX: The Psychological Corporation.

Wilke M, Krageloh-Mann I, Holland SK (2007) Global and local development of gray and white matter volume in normal children and adolescents. Exp Brain Res 178:296-307. 